\title{
Oligonucleotide Synthesis Shared Resource
}

National Cancer Institute

\section{Source}

National Cancer Institute. Oligonucleotide Synthesis Shared Resource. NCI Thesaurus.

Code C39482.

Oligonucleotide Synthesis Shared Resource provides Cancer Center members with custom chemical synthesis of oligonucleotides of defined sequence. 